(1)

CrossMark

\title{
World No Tobacco Day: smoking, nicotine and children
}

\author{
Jørgen Vestbo (ib) ${ }^{1,2}$, Jonathan Grigg ${ }^{3}$, Charlotta Pisinger ${ }^{4,5,6}$ and Andy Bush ${ }^{7}$
}

Affiliations: 'Division of Infection, Immunity and Respiratory Medicine, School of Biological Sciences, The University of Manchester, Manchester, UK. ${ }^{2}$ North West Lung Centre, Manchester University NHS Foundation Trust, Manchester, UK. ${ }^{3}$ Blizard Institute, Queen Mary University, London, UK. ${ }^{4}$ Center for Clinical Research and Prevention, Bispebjerg and Frederiksberg Hospital, Copenhagen, Denmark. ${ }^{5}$ Danish Heart Association, Copenhagen, Denmark. ${ }^{6}$ Dept of Public Health, Faculty of Health Sciences, University of Copenhagen, Copenhagen, Denmark. ${ }^{7}$ Imperial College, London, UK.

Correspondence: Jørgen Vestbo, 2nd Floor, ERC Building, Wythenshawe Hospital, Southmoor Road, Manchester, M23 9LT, UK. E-mail: jorgen.vestbodmanchester.ac.uk

@ERSpublications

In line with @WHO, @EuroRespSoc will work to protect children from being addicted to smoking and nicotine use https://bit.ly/3fNpVas

Cite this article as: Vestbo J, Grigg J, Pisinger C, et al. World No Tobacco Day: smoking, nicotine and children. Eur Respir J 2020; 55: 2001633 [https://doi.org/10.1183/13993003.01633-2020].

31 May, 2020 is World Health Organization (WHO) World No Tobacco Day. The theme this year is "Protecting youth from industry manipulation and preventing them from tobacco and nicotine use" [1]. WHO wishes this year's campaign to serve the following: 1) debunk myths and expose manipulation tactics employed by the tobacco and nicotine industries, particularly marketing tactics targeted at youth, including through the introduction of new and novel products, flavours and other attractive features; 2) equip young people with knowledge about the tobacco and nicotine industries' intentions and tactics to hook current and future generations on tobacco and nicotine products; and 3) empower influencers (in pop culture, on social media, in the home, or in the classroom) to protect and defend youth and catalyse change by engaging them in the fight against Big Tobacco.

The theme is chosen for good reasons. For decades, the tobacco industry has spent a large share of their marketing budget on advertisements directed towards youth [2]. In 2016, the tobacco industry spent USD 26 million each day on marketing [3], and we know from insight into the industry's own documents that marketing directed at children and young adults has always had priority [4]. As late as in 2006, a US judge found that there is overwhelming evidence that the tobacco companies encourage youth to smoke, track youth behaviours and preferences, market to youth based on that tracking, and substantially contribute to youth smoking initiation. The tobacco companies have burnished the image of their youth brands to convey rugged independence, rebelliousness, love of life, adventurousness, confidence, self-assurance, and belonging to the "in" crowd [5].

Some of the tobacco industry's past tactics seem almost absurd today; Camel's "Old Joe" character was clearly invented to appeal to children and in 1991 this brand logo was as well-recognised by 3-6 year-olds as, for example, the logo of the Disney Channel [6]. Advertising like this has long been banned in most countries in Europe, but the tobacco industry knows how to bypass it. As an example, RJ Reynolds has engaged with thousands of consumers through their Camel brand website to design new cigarette packages [7], and Big Tobacco's Instagram hashtags associated with companies' tobacco products have been viewed a staggering 25 billion times; a very effective way to get around existing laws to restrict advertising to 
young people. Furthermore, the tobacco industry has recently made huge investments in alternative nicotine delivery systems, such as smokeless tobacco, heated tobacco and e-cigarettes, the most well-known being Juul.

E-cigarettes and other alternative nicotine delivering devices are being cleverly marketed at youths; not surprisingly, the tobacco industry has transferred their marketing skills to the new industry and apply the same marketing approach. E-cigarette advertising expenditures have increased dramatically, and social media are used extensively. The median number of followers summed across brands reaches over 5 million on Facebook and Instagram alone [8]. At the same time, the tobacco companies are trying to reinvent themselves as concerned and ethical corporations, with initiatives such as the impudent Philip Morris Institute for a Tobacco Free World, and the "Foundation for a Smoke-Free World", also funded by Philip Morris International. What is really needed is an "Institute for a Philip Morris Free World".

The novel nicotine containing products are attractive as they taste of candy, fruit, cake, or another of the at least 15000 flavours, and youth has the misperception that flavoured e-cigarettes are less harmful [9]. The tactics that are used to peddle these wares have included statements that they are safer than tobacco and statements about their advantages as agents to promote smoking cessation.

Firstly, safety and harm. For non-smoking children, this is a non-issue, as it is irrelevant whether or not these products are safer than smoking. Their risk will increase, not decrease, if they use them. All products contain nicotine and are highly addictive. Nicotine is not harmless. Symptoms of mild acute toxicity might include nausea and vomiting, diarrhoea, increased salivation, increased respiratory secretions and bradycardia. Severe poisoning can progress further to seizures and respiratory depression. The human oral fatal dose is commonly reported to be between 50 and $60 \mathrm{mg}$ for adults, with the fatal dose for youth expected to be lower [10].

The evidence is sufficient to conclude that nicotine activates multiple biological pathways through which smoking increases risk for disease. The respiratory and neurological health effects of nicotine have been clearly documented. In addition, nicotine seems to increase the risk of diabetes [11] and nicotine exposure in fetal life can result in multiple adverse consequences [10]. Adolescents' brains are particularly vulnerable to the adverse effects of nicotine. Based on existing knowledge of adolescent brain development, and the results of animal and human studies, it is likely that nicotine exposure during adolescence adversely affects cognitive function and development. Therefore, the potential long-term cognitive effects of exposure to nicotine in adolescents are of great concern [10].

There is also increasing evidence that e-cigarettes cause harm [12-17], from cell models and animal research, as well as single-exposure or short-term studies on humans. These studies have clearly shown that although there is overlapping toxicity, e-cigarettes are not merely a watered-down version of tobacco, but have their own unique toxicities, not least as nicotine is only one of many toxic substances in the novel nicotine-containing products. Acute serious toxicity is well described (e-cigarette or vaping product use associated lung injury, or EVALI); $80 \%$ are likely related to cannabinoids added to the liquids, but $20 \%$ are not. Furthermore, it cannot make Public Health sense to allow the circulation of hardware that can be used to deliver such a risky mix. Let us state it clearly: the acute toxicity of e-cigarettes is significant. Furthermore, it took decades before the horrendous long-term consequences of tobacco were appreciated; we cannot possibly know about the long-term effects of e-cigarettes. Only a fool would be complacent, given the literally thousands of chemicals involved, the uncertainty about the content and toxicity of most of these compounds, and the absolute certainty that many have known toxicities.

Secondly, what about smoking cessation? For non-smoking children smoking cessation is not relevant; it is a non-issue. Regarding smoking adolescents (and adults), it is important to know that no e-cigarette brand has been approved as a smoking cessation aid as there is lack of evidence for their long-term effect. Furthermore, the data on "cessation" merely mean a switch from tobacco to e-cigarettes [18], with all the potential toxicities involved. Although conceivably there are hardcore smokers who can only quit completely with e-cigarettes, in the UK at least they are not approved by the National Institute for Health and Care Excellence as an aid to smoking cessation, and only the most gullible would think that is how they are being marketed. When did you last see nicotine patches being marketed by being attached to an attractive young female's naked arms? Those who advocate for e-cigarettes as agents of smoking cessation must have in place a coherent policy to protect children and young people from these devices.

Finally, are e-cigarettes a gateway to smoking? The answer is yes [19], but who cares? This is a total non-issue. They are a gateway to smoking as well as nicotine addiction, but whether the adolescents progress to smoking or not, we cannot tolerate the appearance of a generation of addicted Darth Vapers as the e-cigarettes per se are harmful. The US Surgeon General has rightly stated that he will not tolerate sitting passively by while a new generation of nicotine addicts is recruited [20]. 
Although the tobacco and vaping industry hails growth of e-cigarette sales as a triumph for public health (they would, wouldn't they?), falsely claiming that more widespread use of e-cigarettes will reduce smoking and the harmful effects of smoking, the European Respiratory Society (ERS) has firmly debunked this myth [21]. Nevertheless, the tobacco and vaping industries are currently using disagreements on the severity of harm among researchers to illustrate the uncertainty in anti-vaping advice; exactly as they used any uncertainty about health effects of smoking in the 1950s and 1960s to promote the sense of little harm being associated with smoking: "Doubt is our product", as stated by one tobacco company [22]. This is another non-issue: is it safer to walk across a motorway with your eyes shut, or a Formula 1 track during a race? Who in their right mind would do either?

We must fight the promotion of nicotine to youths. The tobacco industry would love to be part of this endeavour, but as a Trojan Horse, ensuring they can continue to make money out of addicting young people. The leopard cannot change his spots, but the industry is cleverer than the leopard, and at least tries to repurpose those spots. WHO highlights the involvement of influencers as a way to strengthen the anti-smoking messages to children and adolescents, drawing on their experiences from a large and successful campaign in China [23]. Building on our experiences fighting cigarette smoking in adults a large array of activities, regulations and policies will be required if we are to counter the strong and merciless industry behind all nicotine-containing products. These will need to be adapted for children and young people, the high priority prey for the tobacco industry, in the past, present and in the future. The ERS will be more than happy to contribute to this work. Doubt may be the product of Big Tobacco, but stone cold certainty is that of the Society.

Conflict of interest: J. Vestbo reports personal fees for consultancy and lectures from GlaxoSmithKline, Chiesi Pharmaceuticals, Novartis and AstraZeneca, grants and personal fees for consultancy and lectures from Boehringer Ingelheim, outside the submitted work. J. Grigg reports personal fees for advisory board work from GSK, AstraZeneca and Vifor Pharma, personal fees for lectures from Novartis, outside the submitted work. C. Pisinger has nothing to disclose. A. Bush has nothing to disclose.

\section{References}

1 World Health Organization. World No Tobacco Day - 31 May 2020: Protecting youth from industry manipulation and preventing them from tobacco and nicotine use. www.who.int/news-room/events/detail/2020/ 05/31/default-calendar/world-no-tobacco-day-2020-protecting-youth-from-industry-manipulation-and-preventingthem-from-tobacco-and-nicotine-use Date last accessed: 27 February, 2020.

2 US Department of Health and Human Services. Preventing Tobacco Use Among Youth and Young Adults: A Report of the Surgeon General. Atlanta, US Department of Health and Human Services, Centers for Disease Control and Prevention, National Center for Chronic Disease Prevention and Health Promotion, Office on Smoking and Health, 2012.

3 Federal Trade Commission. Federal Trade Commission Cigarette Report for 2016. Washington, Federal Trade Commission, 2018.

4 Bates C, Rowell A. Tobacco explained. The truth about the tobacco industry ...in its own words. www.who.int/ tobacco/media/en/TobaccoExplained.pdf Date last accessed: 5 May, 2020.

5 Tobacco Control Legal Consortium. The Verdict Is In: Findings from United States v. Philip Morris, The Hazards of Smoking (2006). https://publichealthlawcenter.org/sites/default/files/resources/tclc-verdict-is-in.pdf. Date last accessed: 5 May, 2020.

6 Fischer PM, Schwartz MP, Richards JW, Jr, et al. Brand logo recognition by children aged 3 to 6 years. Mickey Mouse and Old Joe the Camel. JAMA 1991; 266: 3145-3148.

7 Freeman B, Chapman S. Open source marketing: Camel cigarette brand marketing in the "Web 2.0" world. Tob Control 2009; 18: 212-217.

8 O'Brien EK, Hoffman L, Navarro MA, et al. Social media use by leading US e-cigarette, cigarette, smokeless tobacco, cigar and hookah brands. Tob Control 2020; in press [https://doi.org/10.1136/tobaccocontrol-2019055406].

9 Meernik C, Baker HM, Kowitt SD, et al. Impact of non-menthol flavours in e-cigarettes on perceptions and use: an updated systematic review. BMJ Open 2019; 9: e031598.

10 Public Health Service, Office of the Surgeon General. 2014 Surgeon General's Report: The Health Consequences of Smoking-50 Years of Progress. Rockville, MD, US Department of Health and Human Services, 2014.

11 Bruschetta G, Diano S. Brain-to-pancreas signalling axis links nicotine and diabetes. Nature 2019; 574: 336-337.

12 Prochaska JJ. The public health consequences of e-cigarettes: a review by the National Academies of Sciences. A call for more research, a need for regulatory action. Addiction 2019; 114: 587-589.

13 World Health Organization, Department of Communications. E-cigarettes. www.who.int/news-room/q-a-detail/ e-cigarettes-how-risky-are-they. Date last accessed: 26 February, 2020.

14 Garcia-Arcos I, Geraghty P, Baumlin N, et al. Chronic electronic cigarette exposure in mice induces features of COPD in a nicotine-dependent manner. Thorax 2016; 71: 1119-1129.

15 Scott A, Lugg ST, Aldridge K, et al. Pro-inflammatory effects of e-cigarette vapour condensate on human alveolar macrophages. Thorax 2018; 73: 1161-1169.

16 Chung S, Baumlin N, Dennis JS, et al. Electronic cigarette vapor with nicotine causes airway mucociliary dysfunction preferentially via TRPA1 receptors. Am J Respir Crit Care Med 2019; 200: 1134-1145.

17 Kennedy CD, van Schalkwyk MCI, McKee M, et al. The cardiovascular effects of electronic cigarettes: a systematic review of experimental studies. Prev Med 2019; 127: 105770. 
18 Hajek P, Phillips-Waller A, Przulj D, et al. A randomized trial of e-cigarettes versus nicotine-replacement therapy. N Engl J Med 2019; 380: 629-637.

19 Stratton K, Kwan L, Eaton D. Public Health Consequences of E-Cigarettes. The National Academies of Sciences, Engineering and Medicine; Committee on the Review of the Health Effects of Electronic Nicotine Delivery Systems; Board on Population Health and Public Health Practice; Health and Medicine Division, 2018.

20 Department of Health and Human Services. E-Cigarette Use Among Youth and Young Adults: A Report of the Surgeon General-Executive Summary. Atlanta, US Department of Health and Human Services, Centers for Disease Control and Prevention, National Center for Chronic Disease Prevention and Health Promotion, Office on Smoking and Health, 2016.

21 Pisinger C, Dagli E, Filippidis FT, et al. ERS and tobacco harm reduction. Eur Respir J 2019; 54: 1902009.

22 Proctor RN. Golden Holocaust: Origins of the Cigarette Catastrophe and the Case for Abolition. Berkeley and Los Angeles, University of California Press, 2011.

23 World Health Organization. Unleashing the entertainment industry to help create a smoke-free generation in China: Inaugural WHO Partners Forum Case Study. www.who.int/docs/default-source/un-high-level-meeting-ontb/10-china-who-tobacco-campaign.pdf?sfvrsn=9de77d5a_2. Date last accessed: 3 May, 2020. 